\title{
Research on Behavioral Characteristics of the Health Club Group Exercise Participation Population in Xianning City
}

\author{
Yameng $\mathrm{Li}^{1,}$, , Shuangjun $\mathrm{Li}^{2, \mathrm{~b}}$ \\ ${ }^{1}$ Hubei University of Science and Technology, Xianning, Hubei, 437100 \\ ${ }^{2}$ Hubei University of Science and Technology, Xianning, Hubei, 437100
}

Keywords: Xianning City, Group Exercise, Member, Behavior, Characteristics

\begin{abstract}
With lifelong fitness and sports science slogans started, people are increasingly concerned about their own health problems. Forms of exercise fitness group gymnastics loved by the masses, paper Xianning club members for the study, based on survey data population group Exercises basic features and behavioral characteristics were studied and analyzed, with a view to Xianning City Club group exercise provide recommendations and suggestions development Course
\end{abstract}

\section{Introduction}

Group exercise program is one of the club members for the important service products, with respect to personal fitness program put forward, the object is a group practice, with the development of the times, group exercise programs offered in addition to a health club to retain the traditional outside the group fitness program also actively introducing foreign forefront of popular fitness programs to improve their market competitiveness. In recent years, a health club continues is rising in Xianning City and is gradually expanding. Xianning City is evolving sports industry. By Xianning City, a health club membership basic features and behavioral characteristics of a study on the actual situation of members to participate in Xianning City, a health club group exercise programs and propose measures to provide references for the sustainable development of Xianning City, a health club group exercise programs.

\section{Subjects and Methods}

The Study Subjects. The membership in Xianning City Hill Fitness Club, Austria Sofitel Fitness Club, Winds Fitness Club, Flashing Fitness Club, Cosmedix Lake Branch Fitness Club, Moving Force Fitness Club.

Research Methods. In this paper, a review of books on sociology, economics and microeconomic purpose of writing this article and journal articles related to a health club to participate in group exercise history and current development of people to understand. According to research purposes, the use of single-choice and multiple-choice combination of open and closed at the same time developed a way to use this paper needed "Xianning City, a health club group involved in the operation of crowd behavior characteristics of the questionnaire." After this questionnaire about sports sociology expert examination, based on expert feedback and further modified to form a formal questionnaire. 350 questionnaires were distributed and recovered 331, 322 valid questionnaires were returned $92.00 \%$. Application of statistical knowledge, based on the survey made on the operation of the causes of group of people involved in the analysis, and the influence factors involved in people exercise to predict, to analyze health club group of people involved in the operation and development trend of the causes.

Results and Analysis. The basic characteristics of the population involved in mission operations.

Table 1 The age and gender characteristics of population involved in mission operations

\begin{tabular}{cccc}
\hline & Female & Male & Total \\
\hline$<18$ & $6.25 \%$ & $1.88 \%$ & $8.13 \%$
\end{tabular}




$\begin{array}{cccc}18-25 & 20.31 \% & 6.25 \% & 26.56 \% \\ 26-35 & 21.25 \% & 12.19 \% & 33.44 \% \\ 36-45 & 3.13 \% & 3.13 \% & 6.25 \% \\ 46-55 & 4.38 \% & 3.75 \% & 8.13 \% \\ >55 & 11.25 \% & 6.25 \% & 17.50 \% \\ \text { Total } & 66.56 \% & 33.44 \% & 100.00 \%\end{array}$

The number of women involved in the operation of the group far outnumber men in Xianning City Club group operating surveyed the crowd, women accounted for $66.56 \%$, $33.44 \%$ to men only, women limb is more expressive, but also for women selected group exercise type is also more abundant. There are number of different groups involved in the operation of gender differences, there are differences in the number of people of different age groups to participate in the exercise, can be seen from Table 3.2.1, in the age group 18-25 years of operation the number of participants is more, reached the total number of $26.56 \%$, mostly students stage this stage, students Latin, belly dance, JAZZ, and aerobics and other more interested in these types of groups have operated fast-paced, full of dynamic movement, at the same time exercise also you can learn one or two complete dance, when the activity classes or schools can conduct apply, to show their own style. 26-45 years old this age, most people involved in group exercise, reaching $33.44 \%$. This stage, mostly just out of school to work stable, organized a family.

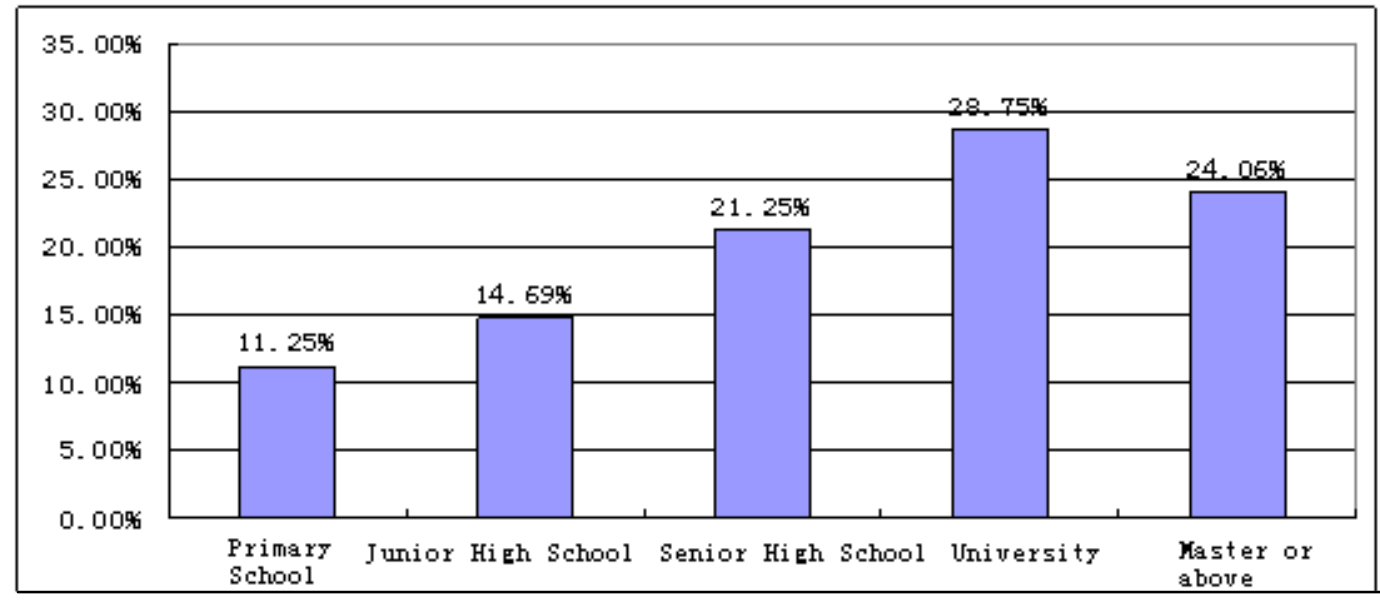

Figure 2 The education characteristics of population involved in the operation groups

A person's qualifications to a certain extent, determines the different values to develop his and cognition. Study, the group involved in the operation of the club, mostly high school diploma, bachelor's degree, master's degree or above. Where university education is the main force reached $28.75 \%$, students' participation in group exercise activity is pretty much for promotions or publicity to be students, can get better results. Master's degree and master's degree or populations groups

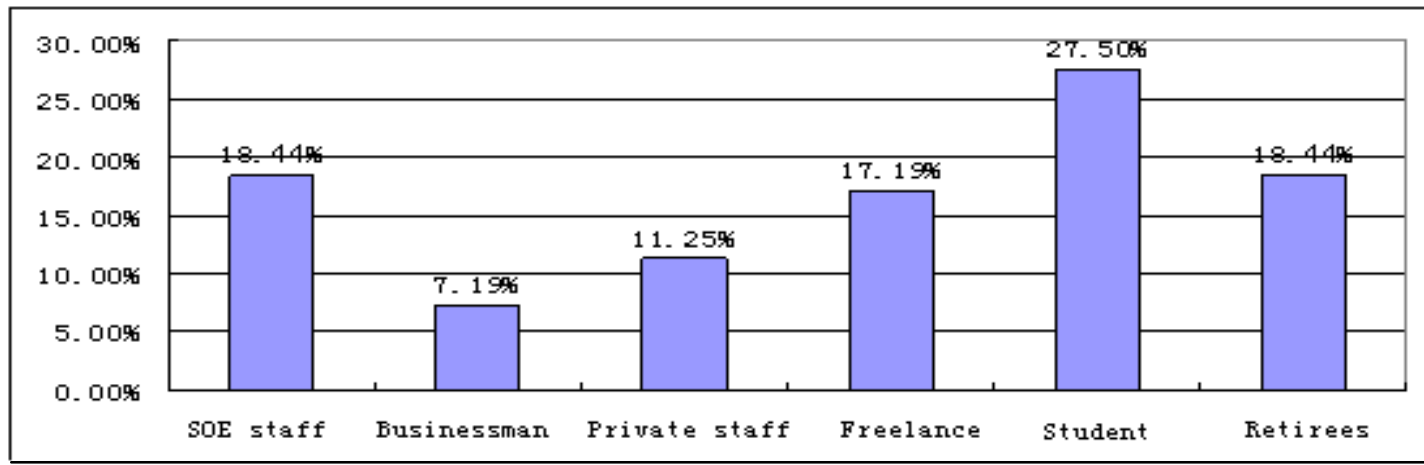

Figure 2 The occupational characteristics of population involved in operating group

People of different occupations, idle time is not the same, the crowd participation, accounting for $27.5 \%$ of students in class time is fixed, required classes Monday to Friday, Saturday and Sunday 
you can group Exercises, and idle time than college students more and more free, students use exercise group exercise, body shape or learn a certain expertise. The proportion of state-owned enterprise staff and retirees have reached 18.44 percent, state-owned enterprises staff working hours more fixed classes, Monday to Friday, nine to five, after work a longer time discretionary use of group operations to ease the day's work pressure, the weekend can have free time, take advantage of group exercises to relieve stress can further enhance their temperament and so on.

Behavior Characteristics of Population Involved in Mission Operations.

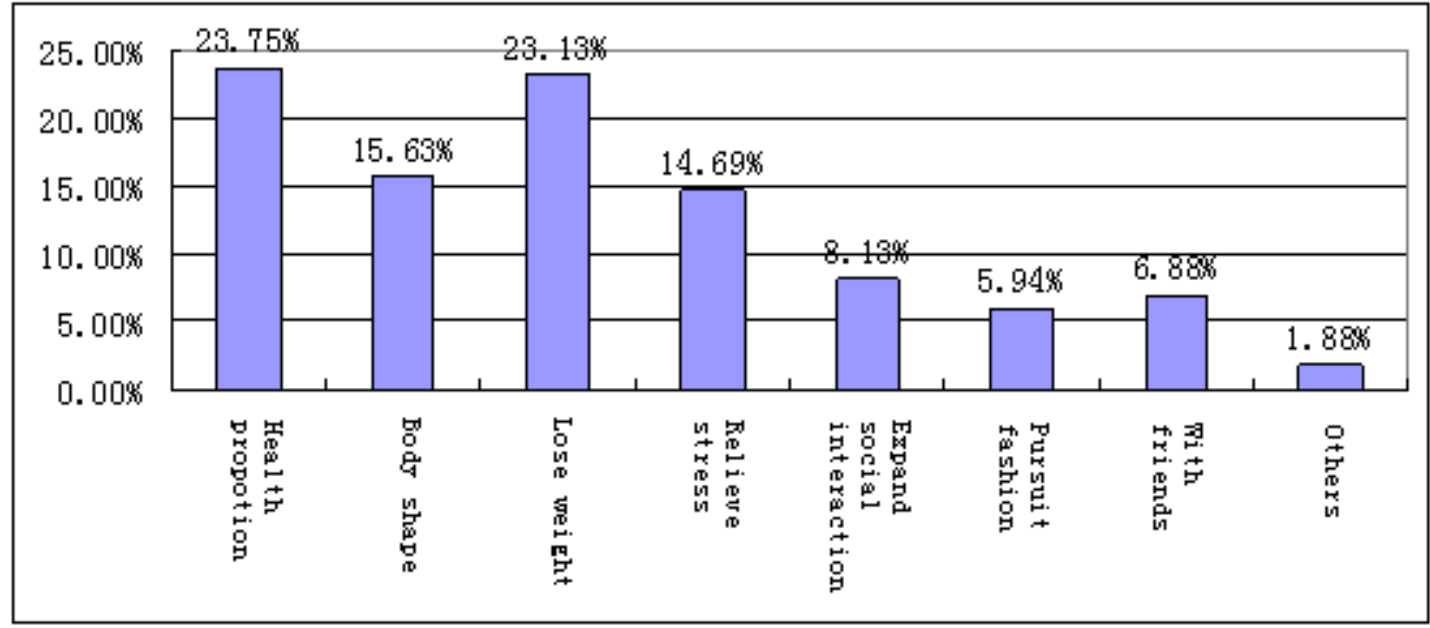

Figure 3 The motivation of people involved in operating group

Group Exercises not only to improve the movement of the bodily functions, but also bring body shape, relieve stress and expand the added value of social interaction circle and so on. $23.75 \%$ of the people in order to promote good health and participate in group Exercises, shows that people are increasingly concerned about health problems, is no longer the sick and then go to the doctor's status, but the beginning of a positive exercise. There are $23.13 \%$ of the people in order to lipid-lowering diet, now people's living standard is getting better, the daily intake of nutrients is more sophisticated and rich, and the corresponding training opportunities and labor is less and less.

The Course Type of People Involved in the Mission Operations.

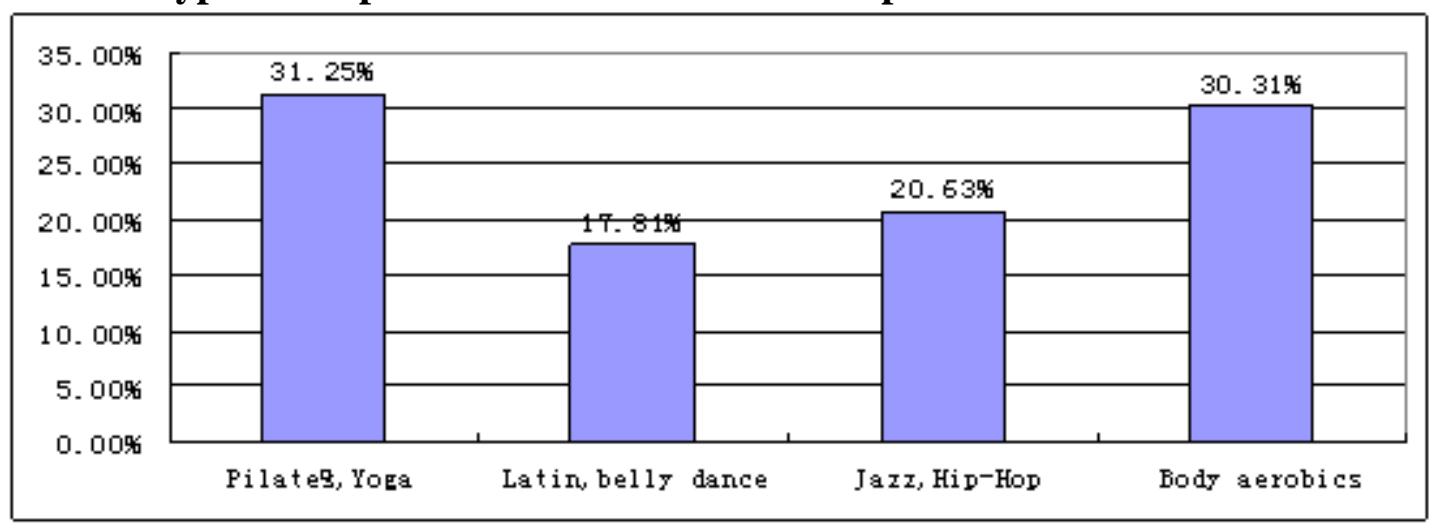

Figure 4 The course type of people involved in the mission operations.

$31.25 \%$ of the personnel participating in yoga and Pilates. Yoga and Pilates are all relatively static muscle thrust of the project, by raising awareness of the participants, helping people play to their potential method, it is possible to reach the final body, a psychic and spiritual harmony. There are $30.31 \%$ of people choose the form and aerobics courses, weight control and body movement, operating frequency and amplitude is large, can achieve the purpose of enhancing lipid-lowering diet and physical fitness. JAZZ and hip-hop are some more choice in school, this type of strong dance rhythms, full of dynamic flexibility, and physical activity full of fun and a sense of rhythm, young people express their way.

Satisfaction of the Population Participation in League Exercises 


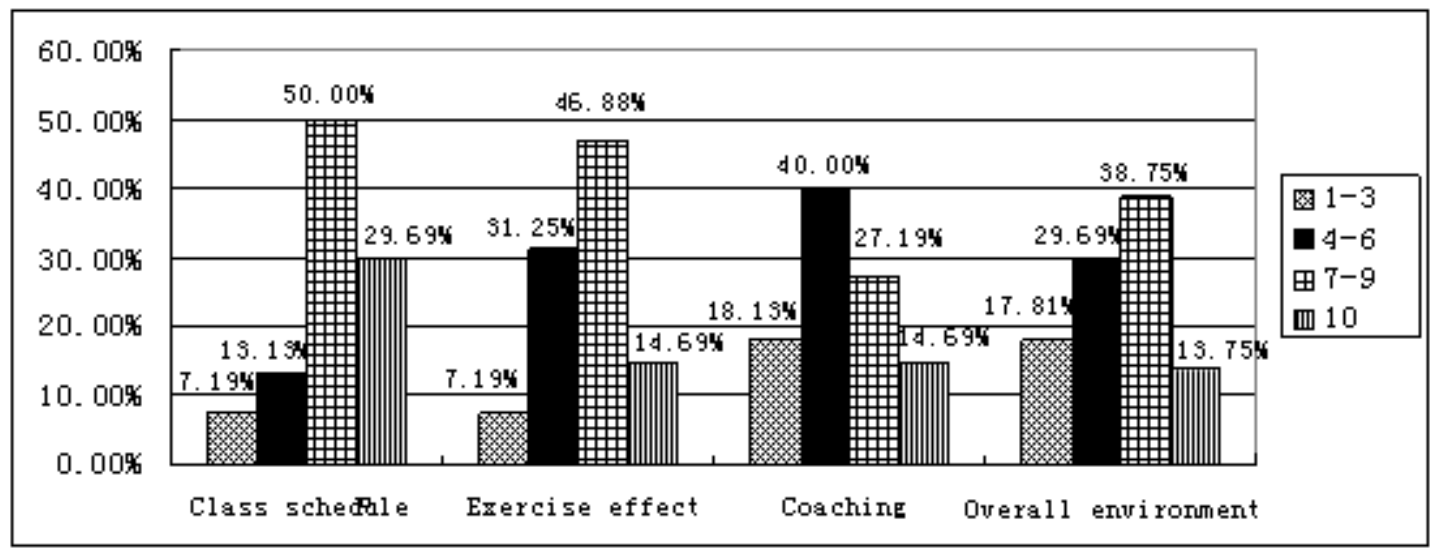

Figure 5 The satisfaction of people involved in operating group

Let people participate in group Exercises for curriculum, training effect, coaching and overall environment was evaluated. $50.00 \%$ of people rating of $7-9$ minutes, $29.69 \%$ of people rating of 10 points, indicating Xianning City club in the curriculum, or more properly, can meet the needs of most people. Investigating the effect of exercise satisfaction, and 31.25 percent of the people given a rating of 4-6 points is not particularly satisfied, which may group gymnastics classes the way, there are about 20-40 people group exercise classes, different different ages on the basis of the same study will be a difference, causing some participants inner gap. And the effect of exercise are not well appear in the short term, long-term adherence, many group exercise participants on the effect of exercise can also cause the expected value of the larger gap.

\section{Conclusions}

The group operating mainly in the female-dominated crowd participation, in terms of age but mainly just out of school and have some basis of mainly young people; participation in group Exercises educated population is relatively high, mainly high school education, college students and population-based master's degree. And occupational and income groups operating on the participation of affected people is also great, students, staff and retired employees of these state-owned enterprises more time, more liberal groups were more likely to participate in group exercise workout.

Found: The scientific research project of 2014 (ky14033); Humanities and social sciences research project of Hubei Provincial Department of Education (15Q225)

\section{References}

[1] Xinli Wang: Chengdu Sport University, Vol. 8 (2011) No 37, p.26-28

[2] People's Republic of China National Standard Bathing Places Part 2. The classification and evaluation of the gym, 2001 